\title{
Kontrol Tracking Fuzzy untuk Sistem Pendulum Kereta Menggunakan Pendekatan Linear Matrix Inequalities
}

\author{
Rizki Wijayanti, Trihastuti Agustinah \\ Departemen Teknik Elektro - Fakultas Teknologi Elektro Institut Teknologi Sepuluh Nopember \\ E-mail: trihastuti@elect-eng.its.ac.id
}

\begin{abstract}
Abstrak-Sistem Pendulum Kereta adalah suatu plant nonlinear dan tidak stabil yang terdiri dari batang pendulum yang berayun searah atau berlawanan arah jarum jam dan bersumbu pada kedua sisi kereta yang dapat bergerak secara horisontal. Makalah ini membahas tentang kontrol tracking berbasis model servo tipe 1 dengan plant tanpa integrator agar Sistem Pendulum Kereta mampu bergerak mengikuti sinyal referensi berupa sinyal step. Model nonlinear Sistem Pendulum Kereta direpresentasikan dengan model fuzzy Takagi-Sugeno dengan didasarkan aturan PDC (Paralel Distributed Compensation) untuk memperoleh aturan kontroler. Gain state feedback dan gain integrator diperoleh dengan menggunakan pendekatan LMI (Linear Matrix Inequalities). Hasil simulasi menunjukkan bahwa posisi kereta mampu mengikuti sinyal referensi berupa sinyal step dengan nilai IAE (Integral Absolute Error) sebesar 0,1986 m.
\end{abstract}

Kata Kunci-Sistem Pendulum Kereta, Tracking, Fuzzy Takagi Sugeno, Sistem Servo Tipe 1, Linear Matrix Inequalities.

\section{PENDAHULUAN}

$\mathrm{S}$ ISTEM Pendulum Kereta merupakan salah satu sistem yang sangat penting untuk penelitian di bidang kontrol. Berbagai teori metode kontrol banyak diuji dan dibandingkan melalui pengujian terhadap Sistem Pendulum Kereta. Hal ini dikarenakan Sistem Pendulum Kereta merupakan sistem nonlinear dan tidak stabil serta dapat dilinearkan di sekitar titik keseimbangannya. Sistem Pendulum Kereta adalah suatu plant yang terdiri dari batang pendulum yang bergerak secara rotasi searah atau berlawan arah jarum jam dan bersumbu pada kedua sisi kereta yang dapat bergerak secara vertikal pada suatu lintasan. Tujuan utama dari penelitian ini adalah merancang kontrol fuzzy T-S menggunakan pendekatan LMI dengan batasan penempatan pole. Hasil yang diharapkan adalah nilai error tracking mendekati nol dengan sinyal referensi step melalui optimasi menggunakan LMI.

Beberapa metode telah dikembangkan untuk menangani permasalahan tracking. Pada [1] kontrol tracking menggunakan model fuzzy T-S berbasis kontrol optimal. Kontrol tracking berbasis model following telah dikembangkan pada [2]. Sistem kontrol tracking berbasis Sistem Servo Tipe 1 untuk plant tanpa integrator juga telah diterapkan pada [3] dengan menggunakan metode pole placement.

Penyelesaian permasalahan dari Sistem Pendulum Kereta menggunakan desain Sistem Servo Tipe 1 dengan plant tanpa integrator menggunakan pendekatan LMI
(Linear Matrix Inequality) untuk bisa mendapatkan nilai gain kontroler dan gain integrator diharapakan dapat memberikan respon yang lebih baik agar plant dapat mengikuti sinyal referensi berupa sinya step. Karakteristik Sistem Pendulum Kereta yang nonlinear direpresentasikan ke dalam model linear dengan model fuzzy T-S yang didasarkan pada aturan PDC (Paralel Distributed Compensation).

\section{MODEL MATEMATIKA}

Sistem Pendulum Kereta merupakan sebuah benchmark yang digunakan untuk menguji suatu metode kontrol. Sistem Pendulum kereta merupakan sistem nonlinear. Sistem Pendulum Kereta terdiri dari sepasang batang pendulum yang bebas berayun secara vertikal dan terpasang pada kereta yang bergerak horizontal pada suatu lintasan dengan panjang lintasan tertentu.

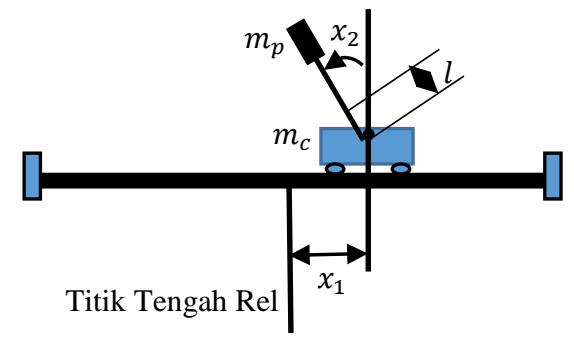

Gambar 1. Diagram Fisik Sistem Pendulum Kereta

Model matematika Sistem Pendulum Kereta dalam bentuk persamaan state dapat dituliskan sebagai berikut:

$\dot{x}_{1}=x_{3}$

$\dot{x}_{2}=x_{4}$

$\dot{x}_{3}=\frac{a\left(u-T_{c}-\mu x_{4}^{2} \sin x_{2}\right)+l \cos x_{2}\left(\mu g \sin x_{2}-f_{p} x_{4}\right)}{J+\mu l \sin ^{2} x_{2}}$

$\dot{x}_{4}=$

$\frac{l \cos x_{2}\left(u-T_{C}-\mu x_{4}{ }^{2} \sin x_{2}\right)+\mu g \sin x_{2}-f_{p} x_{4}}{J+\mu l \sin ^{2} x_{2}}$

dengan

$$
\begin{aligned}
& a=l^{2}+\frac{J}{m_{c}+m_{p}} \\
& \mu=\left(m_{c}+m_{p}\right) l
\end{aligned}
$$

\section{SISTEM KONTROL TRACKING}

Struktur kontrol tracking menggunakan struktrur servo tipe 1 dirancang untuk mengontrol posisi kereta agar dapat mengikuti sinyal referensi yang diberikan. Sinyal referensi berupa sinyal step.

Sistem nonlinear Sistem Pendulum Kereta dapat didekati menjadi sistem linear berdasarkan hasil linearisasi 
lokal di sekitar titik ekuilibriumnya dan dapat direpresentasikan pada persamaan berikut:

$$
\dot{x}=f(x)+h(x, u)
$$

Pada penelitian ini linearisasi dilakukan pada tiga daerah kerja, yaitu \pm 0 radian, $\pm 0,3$ radian, $\pm 0,5$ radian.

$f(x)=\left[\begin{array}{l}f_{1}(x) \\ f_{2}(x) \\ f_{3}(x) \\ f_{4}(x)\end{array}\right]=\left[\begin{array}{c}x_{3} \\ x_{4} \\ \frac{a\left(u-T_{c}-\mu x_{4}^{2} \sin x_{2}\right)+l \cos x_{2}\left(\mu g \sin x_{2}-f_{p} x_{4}\right)}{J+\sin ^{2} x_{2}} \\ \frac{l \cos x_{2}\left(u-T_{c}-\mu x_{4}^{2} \sin x_{2}\right)+\mu g \sin x_{2}-f_{p} x_{4}}{J+\mu l \sin ^{2} x_{2}}\end{array}\right]$

$h(x, u)=\left[\begin{array}{l}h_{1}(x, u) \\ h_{2}(x, u) \\ h_{3}(x, u) \\ h_{4}(x, u)\end{array}\right]=\left[\begin{array}{c}0 \\ 0 \\ \frac{a u}{J+\mu l \sin ^{2} x_{2}} \\ \frac{u l \cos x_{2}}{J+\mu l \sin ^{2} x_{2}}\end{array}\right]$

erja pertama :

$x_{2}=0, x=\left[\begin{array}{cccc}0 & 0 & 0 & 0\end{array}\right]^{T}$ dan $u=0$ diperoleh $\dot{x}=A_{1} x+B_{1} u$

dengan

$\boldsymbol{A}_{\mathbf{1}}=\left[\begin{array}{cccc}0 & 0 & 1 & 0 \\ 0 & 0 & 0 & 1 \\ 0 & 0,2541 & 0 & -0,0001 \\ 0 & 15,1225 & 0 & -0,0074\end{array}\right] ; \boldsymbol{B}_{\mathbf{1}}=\left[\begin{array}{c}0 \\ 0 \\ 0,8274 \\ 1,2444\end{array}\right]$

Untuk titik kerja kedua :

$x_{2}= \pm 0,3, x=\left[\begin{array}{llll}0 & \pm 0,3 & 0 & 0\end{array}\right]^{T}$ dan $u=0$ diperoleh $\dot{x}=A_{2} x+B_{2} u$

dengan

$\boldsymbol{A}_{2}=\left[\begin{array}{cccc}0 & 0 & 1 & 0 \\ 0 & 0 & 0 & 1 \\ 0 & 0,2082 & 0 & -0,0001 \\ 0 & 14,3493 & 0 & -0,0074\end{array}\right] ; \boldsymbol{B}_{2}=\left[\begin{array}{c}0 \\ 0 \\ 0,8255 \\ 1,1862\end{array}\right]$

Untuk titik kerja ketiga :

$x_{2}= \pm 0,5, x=\left[\begin{array}{llll}0 & \pm 0,5 & 0 & 0\end{array}\right]^{T}$ dan $u=0$ diperoleh dengan

$\boldsymbol{A}_{3}=\left[\begin{array}{cccc}0 & 0 & 1 & 0 \\ 0 & 0 & 0 & 1 \\ 0 & 0,1342 & 0 & -0,0001 \\ 0 & 13,0363 & 0 & -0,0074\end{array}\right] ; \boldsymbol{B}_{3}=\left[\begin{array}{c}0 \\ 0 \\ 0,8225 \\ 1,0856\end{array}\right]$

Matriks keluaran untuk ketiga titik kerja adalah:

$\mathrm{C}_{1}=\mathrm{C}_{3}=\mathrm{C}_{3}=\left[\begin{array}{llll}1 & 0 & 0 & 0\end{array}\right]$

Berdasarkan nilai matriks $A$ dan $B$, dapat dibangun model fuzzy T-S untuk aturan plant sebagai berikut :

Aturan plant ke-1:

if $x_{2}(\mathrm{t})$ is $M_{1}$ (Sekitar 0 radian)

Then $\dot{x}(t)=A_{1} x(t)+B_{1} u(t)$

$$
y(t)=C_{1} x(t)
$$

Aturan plant ke-2:

$$
\begin{aligned}
& \dot{x}=A x+B u \\
& y=C x \\
& \dot{\xi}=r-y=r-C x
\end{aligned}
$$

maka dapat dibuat augmented system

$$
\left[\begin{array}{l}
\dot{x}(t) \\
\dot{\xi}(t)
\end{array}\right]=\left[\begin{array}{cc}
A & 0 \\
-C & 0
\end{array}\right]\left[\begin{array}{l}
x(t) \\
\xi(t)
\end{array}\right]+\left[\begin{array}{l}
B \\
0
\end{array}\right] u(t)+\left[\begin{array}{l}
0 \\
1
\end{array}\right] r(t)
$$

dimana

$$
\bar{A}=\left[\begin{array}{cc}
A & 0 \\
-C & 0
\end{array}\right] ; \bar{B}=\left[\begin{array}{c}
B \\
0
\end{array}\right]
$$

dan sinyal kontrol

$$
\mathbf{u}=-\overline{\mathbf{K}} \overline{\mathbf{x}}
$$

dimana

$$
\bar{K}=-\left[\begin{array}{ll}
K & k_{I}
\end{array}\right]
$$

dengan $K$ adalah gain feedback dan $k_{I}$ adalah gain integrator. $K$ dan $k_{I}$ dapat dihitung menggunakan pendekatan Linear Matrix Inequelity (LMI).

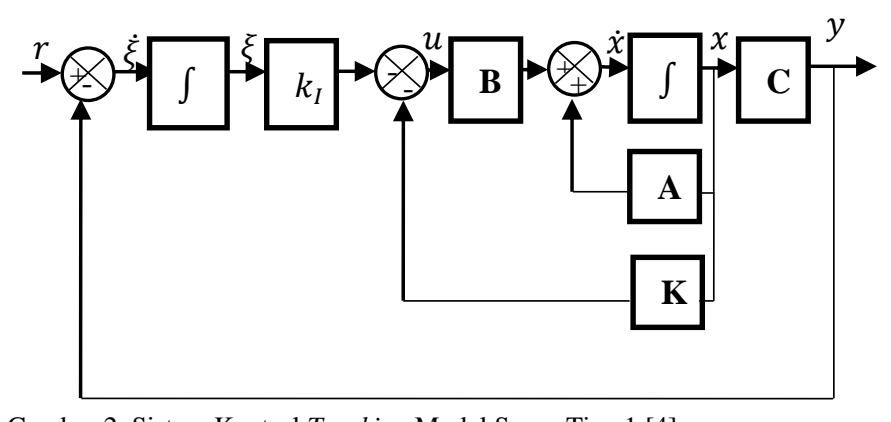

Gambar 2. Sistem Kontrol Tracking Model Servo Tipe 1 [4]

Berdasarkan Persamaan (12) dapat dibentuk tiga subsistem close loop untuk ketiga model linear sistem pendulum kereta sebagai berikut:

$\dot{\bar{x}}=\bar{A}_{i} x+\bar{B}_{i} u$

atau

$\dot{\bar{x}}=\left[\begin{array}{cc}A_{i} & 0 \\ -C_{i} & 0\end{array}\right] x+\left[\begin{array}{c}B_{i} \\ 0\end{array}\right] u \quad, i=1,2,3$

dengan

$\bar{A}_{1}=\left[\begin{array}{ccccc}0 & 0 & 1 & 0 & 0 \\ 0 & 0 & 0 & 1 & 0 \\ 0 & 0,2541 & 0 & -0,0001 & 0 \\ 0 & 15,1225 & 0 & -0,0074 & 0 \\ -1 & 0 & 0 & 0 & 0\end{array}\right] ; \bar{B}_{1}=\left[\begin{array}{c}0 \\ 0 \\ 0,8274 \\ 1,2444 \\ 0\end{array}\right]$

if $x_{2}(\mathrm{t})$ is $M_{2}( \pm 0,3$ radian)

Then $\dot{x}(t)=\dot{x}(t)=A_{2} x(t)+B_{2} u(t)$ 
$\bar{A}_{2}=\left[\begin{array}{ccccc}0 & 0 & 1 & 0 & 0 \\ 0 & 0 & 0 & 1 & 0 \\ 0 & 0,2082 & 0 & -0,0001 & 0 \\ 0 & 14,3493 & 0 & -0,0074 & 0 \\ -1 & 0 & 0 & 0 & 0\end{array}\right] ; \bar{B}_{2}=\left[\begin{array}{c}0 \\ 0 \\ 0,8255 \\ 1,1862 \\ 0\end{array}\right]$

$$
\bar{A}_{3}=\left[\begin{array}{ccccc}
0 & 0 & 1 & 0 & 0 \\
0 & 0 & 0 & 1 & 0 \\
0 & 0.1342 & 0 & -0,0001 & 0 \\
0 & 13,0363 & 0 & -0.0074 & 0 \\
-1 & 0 & 0 & 0 & 0
\end{array}\right] ; \bar{B}_{3}=\left[\begin{array}{c}
0 \\
0 \\
0,8255 \\
1,0856 \\
0
\end{array}\right]
$$

Berdasarkan matrik augmented $\bar{A}_{i}$ dan $\bar{B}_{i}$ maka diperoleh nilai $K_{i}$ dan $k_{I i}$. Sehingga dapat ditentukan aturan kontroler yang bersesuaian dengan aturan plant pada Persamaan (8) sampai (10) sebagai berikut:

Aturan kontroler ke-1:

if $x_{2}(\mathrm{t})$ is $M_{1}$ (Sekitar 0 radian)

Then $\boldsymbol{u}(\mathrm{t})=-\overline{\boldsymbol{K}}_{1} \boldsymbol{x}(t)$

Aturan kontroler ke-2:

$$
\text { if } x_{2}(\mathrm{t}) \text { is } M_{2}( \pm 0,3 \text { radian })
$$$$
\text { Then } \boldsymbol{u}(\mathrm{t})=-\overline{\boldsymbol{K}}_{2} \boldsymbol{x}(t)
$$

Aturan kontroler ke-3:

$$
\begin{aligned}
& \text { if } x_{2}(\mathrm{t}) \text { is } M_{3}( \pm 0,5 \text { radian }) \\
& \text { Then } \boldsymbol{u}(\mathrm{t})=-\overline{\boldsymbol{K}}_{3} \boldsymbol{x}(t)
\end{aligned}
$$

Untuk mendapatkan nilai gain feedback dan gain integrator digunakan algoritma LMI. Jika matrik $P$ definit positif maka sistem loop tertutup bersifat stabil asimtotik. $\left[\left(\bar{A}_{\imath}-\bar{B}_{l} K_{j}\right)^{T} P+P\left(\bar{A}_{\imath}-\bar{B}_{l} K_{j}\right)\right]<0, i=1,2, \ldots, r$

$G_{i j}{ }^{T} P+P G_{i j}<0$

$$
, i<j \leq r
$$

dengan

$$
G_{i j}=\frac{\overline{A_{l}}-\bar{B}_{l} K_{j}+\bar{A}_{j}-\bar{B}_{J} K_{i}}{2}
$$

pre multiplying dan post multiplying kedua sisi pertidaksamaan dengan $P^{-1}$ dan dengan menggunakan variabel peubah:

$$
\begin{aligned}
& P^{-1}=Q \\
& K_{i} Q=Y
\end{aligned}
$$

sehingga Persamaan (23) dan (24) menjadi

$\bar{A}_{\imath} Q+Q \bar{A}_{\imath}^{-1}-\bar{B}_{\imath} Y_{i}-Y_{i}^{T} \bar{B}_{\imath}^{T}<0 \quad, i=1,2, \ldots, r$

$\frac{1}{2}\left[\left(\bar{A}_{\imath} Q+Q \bar{A}_{\imath}^{-1}-\bar{B}_{\imath} Y_{j}-Y_{j}^{T} \bar{B}_{\imath}^{T}\right)\right.$

$+\frac{1}{2}\left[\left(\bar{A}_{\imath} Q+Q \bar{A}_{\iota}^{-1}-\bar{B}_{\imath} Y_{i}-Y_{i}^{T} \bar{B}_{\imath}^{T}\right)\right]<0 \quad, i<j \leq r$

Untuk mendapatkan hasil yang lebih baik, pada penelitian ini digunakan batasan berupa penempatan pole. Menurut Chilali dan Gahinet [5], daerah LMI diilustrasikan pada Persamaan 25, yaitu

$D_{q, r}=\left\{x+j y \in C:(x+q)^{2}+y^{2}<r^{2}\right.$

Persamaan (25), jika diilustrasikan kedalam gambar akan membentuk lingkaran dengan titik pusat lingkaran (- q, 0) dan jari-jari lingkaran $r$ (dengan $r>0)$. Lingkaran tersebut berada sebelah kiri sumbu imajiner seperti pada Gambar 3.

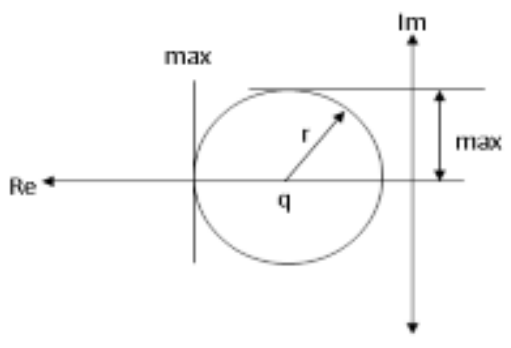

Gambar 3. Lokasi Pole dari Lingkaran Daerah D

Jika $\lambda=-\varsigma \omega_{n}+j \omega_{d}$ diasumsikan merupakan pole komplek pada $D_{q, r}$, maka harus memenuhi kriteria berikut ini

$$
\begin{aligned}
& \varsigma>\sqrt{1-\left(r^{2} / q^{2}\right)} \\
& \omega_{n}<q+r \\
& \omega_{d}<r
\end{aligned}
$$

Sistem kontrol fuzzy akan stabil pada daerah D (dengan semua pole komplek berada pada daerah D) jika dan hanya jika memenuhi persamaan berikut ini.

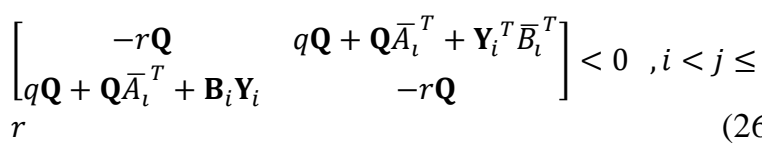

\section{HASIL DAN ANALISA}

Simulasi dilakukan dengan kondisi awal sudut pendulum adalah 0,3 radian. Kondisi awal untuk posisi kereta, kecepatan kereta dan kecepatan sudut pendulum adalah 0. Sedangkan sinyal referensi yang diberikan adalah sinyal step

Kondisi penempatan daerah pole yang diinginkan adalah: Pertama $: r=32$ dan $q=70$

Kedua $: r=72$ dan $q=150$

Ketiga $: r=162$ dan $q=330$

Simulasi dilakukan dengan kondisi awal sudut pendulum adalah 0,3 radian. Kondisi awal untuk posisi kereta, kecepatan kereta dan kecepatan sudut pendulum adalah 0 .

Pada Gambar 3 menunjukkan posisi kereta pada sistem pendulum kereta dalam satuan meter untuk ketiga kondisi penempatan pole. Terlihat bahwa respon posisi kereta pada ketiga kondisi penempatan pole dapat melakukan tracking terhadap sinyal referensi yang diberikan. Pada penempatan pole pertama memiliki nilai overshoot $-0,133$ meter dan waktu yang dibutuhkan agar kereta dapat mengikuti sinyal referensi sebesar 5,5 detik. Nilai respon posisi kereta memiliki nilai overshoot sebesar - 0,118 pada penempatan pole kedua dan nilai overshoot sebesar -0,112 dengan waktu agar posisi kereta dapat mengikuti sinyal referensi sama pada penempatan pole pertama yaitu 5,5 detik. 


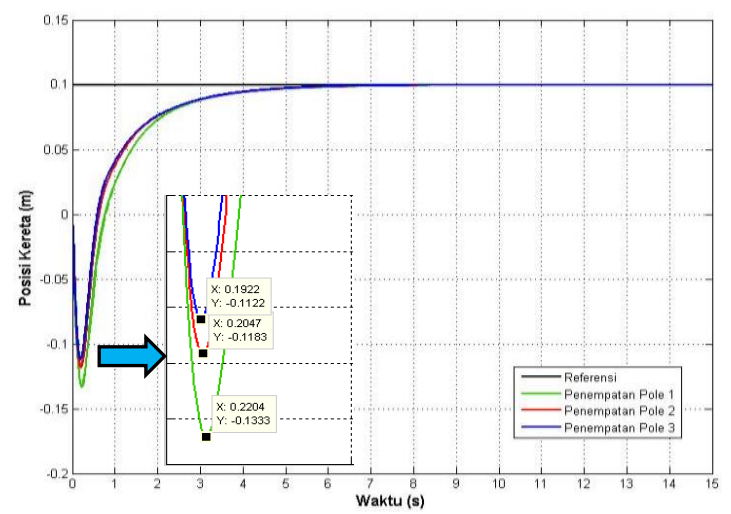

Gambar 4. Posisi Kereta pada Simulasi Variasi Penempatan Pole

Simulasi dengan berbagai kondisi awal disimulasikan dengan memberikan kondisi awal pada sudut pendulum yaitu 0,3 radian dan 0,5 radian. Kondisi awal untuk posisi kereta, kecepatan kereta dan kecepatan sudut pendulum adalah 0. Pada simulasi ini digunakan skenario penempatan pole yang ketiga, dengan $[\mathrm{r}, \mathrm{q}]=[162,330]$ karena memiliki hasil respon yang lebih baik dibandingkan dengan penempatan daerah pole yang lain dan nilai IAE yang terkecil.

Pada Gambar 4 menunjukkan respon posisi kereta dalam satuan meter dengan berbagai kondisi awal pada sudut pendulum. Respon menunjukkan bahwa posisi kereta pada kedua kondisi awal dapat melakukan tracking dengan mengikuti nilai referensi yang diberikan. Pada kondisi awal 0,3 rad respon memiliki overshoot sebesar 0,112 rad. Sedangkan pada kondisi awal kedua, yaitu 0,5 rad nilai overshoot sebesar $-0,15$ rad.

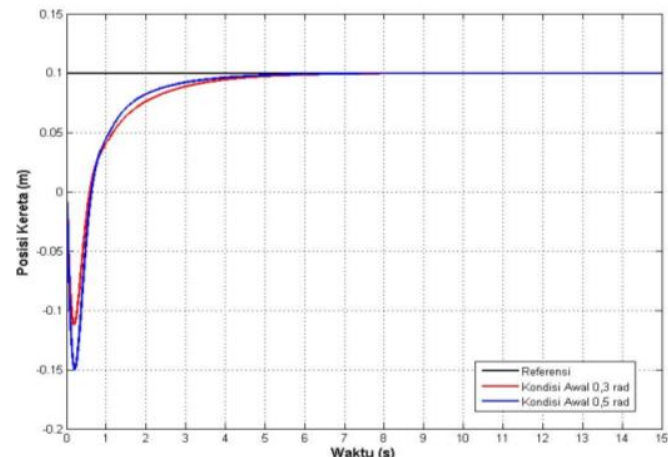

Gambar 5. Posisi Kereta pada Simulasi dengan Berbagai Kondisi Awal

Gambar 5 menunjukkan posisi kereta ketika sistem diberikan gangguan. Ketika gangguan diberikan terjadi penyimpangan sekitar 0,012 meter. Selanjutnya sistem dapat mengatasi gangguan dan kembali mengikuti sinyal referensi setelah 11 detik.

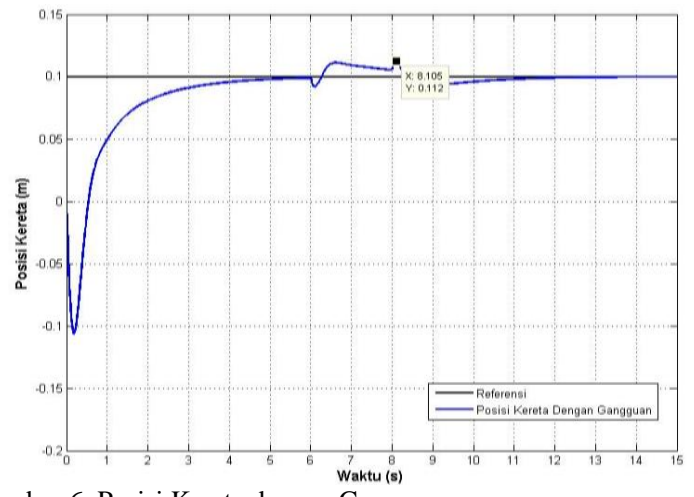

Gambar 6. Posisi Kereta dengan Gangguan
Pada simulasi kedua digunakan sinyal referensi sinus yang dihasilkan dari Signal Generator yang dapat ditemukan di library source pada Simulink.

Gambar 6 menampilkan hasil simulasi posisi kereta dengan sinyal referensi berupa sinyal sinus, dengan membandingkan beberapa kondisi penempatan pole.

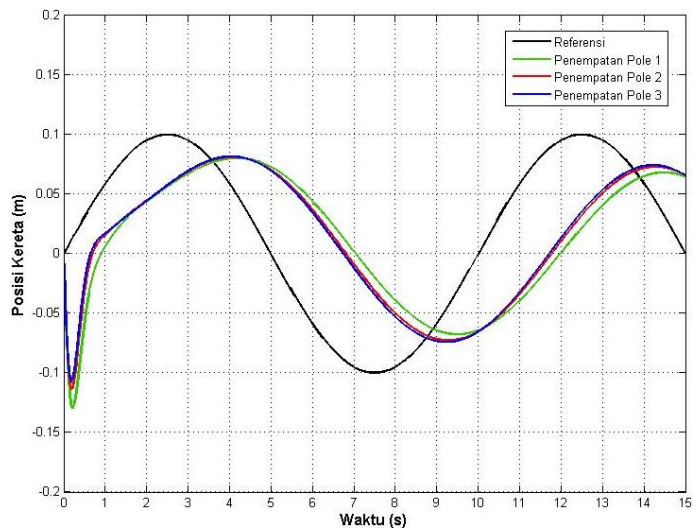

Gambar 7. Posisi Kereta pada Simulasi Varaisi Penempatan Pole dengan Referensi Sinyal Sinus

Pada simulasi digunakan variasi penempatan pole yang ketiga yaitu $[\mathrm{r}, \mathrm{q}]=[162,330]$ dengan berbagai kondisi awal. Kondisi awal sudut pendulum yang digunakan adalah 0,3 radian dan 0,5 radian.

Gambar 7 menunjukkan posisi kereta dalam satuan meter dengan kedua kondisi awal sudut pendulum.

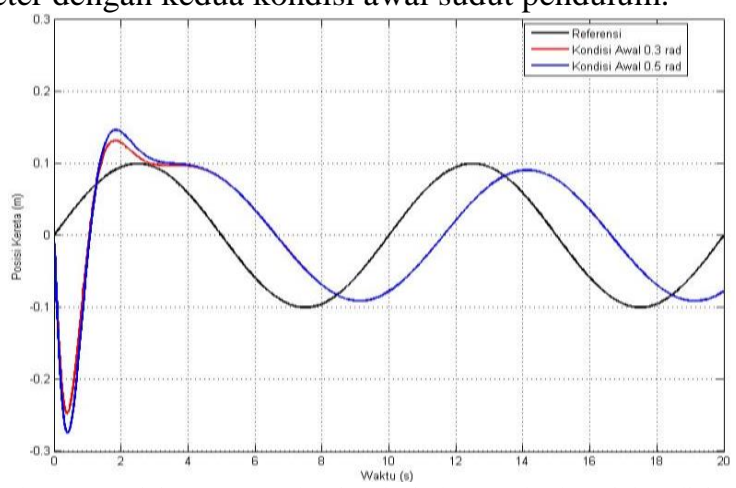

Gambar 8. Posisi Kereta pada simulasi dengan berbagai kondisi awal menggunakan referensi sinyal sinus

\section{KESIMPULAN}

Setelah melakukan pengujian pada makalah ini menggunakan sistem kontrol fuzzy Takagi-Sugeno dengan struktur Sistem Servo Tipe 1 dengan plant tanpa integrator yang telah dirancang menggunakan pendekatan LMI (Linear Matrix Inequalies) dapat diambil kesimpulan sebagai berikut:

1. Hasil simulasi dari sistem kontrol fuzzy TakagiSugeno yang telah dibuat menunjukkan bahwa posisi kereta dapat mengikuti masukan berupa sinyal referensi step dengan batang pendulum dapat distabilkan pada titik di sekitar nol radian.

2. Beda fase yang terjadi ketika sinyal referensi yang diberikan berupa sinyal sinus menunjukkan bahwa kereta dapat mengikuti referensi tetapi terdapat beda fase

3. Berdasarkan simulasi yang dilakukan didapatkan hasil respon terbaik dihasilkan dengan menggunakan penempatan pole $[\mathrm{r}, \mathrm{q}]=[162,330]$ dan kondisi awal sudut pendulum yaitu 0,3 radian 
4. Hasil simulasi untuk sinyal referensi step melalui optimasi menggunkan LMI menghasilkan nilai IAE (Integral Absolute Error) sebesar 0,1986 m.

\section{DAFTAR PUSTAKA}

[1] R. P. Adenia, "Kontrol Tracking Fuzzy-Optimal untuk Sistem Pendulum Kereta," ITS, 2013.

[2] J. H. S. Putra, "Kontrol Tracking Fuzzy Menggunakan Model Following Untuk Sistem Pendulum Kereta," ITS, 2016.

[3] H. Indrawati, "Kontrol Fuzzy Takagi-Sugeno Berbasis Sistem Servo Tipe 1 Untuk Sistem Pendulum Kereta," ITS, 2013.

[4] K. Ogata, Modern Control Engineering, "3rd ed. New Jersey: Prentice-Hall, 1997.

[5] M. C. and P. Gahinet, "Hळ Design with Pole Placement Constraints: An LMI Approach," IEEE Trans. Autom. Control, vol. 41, pp. 358-367, 1996. 